\title{
Behavioral Stress Modifies Hippocampal Synaptic Plasticity through Corticosterone-Induced Sustained Extracellular Signal-Regulated Kinase/Mitogen-Activated Protein Kinase Activation
}

\author{
Chih-Hao Yang, ${ }^{1,2}$ Chiung-Chun Huang, ${ }^{1}$ and Kuei-Sen $\mathrm{Hsu}^{1,2}$ \\ ${ }^{1}$ Department of Pharmacology and ${ }^{2}$ Institute of Basic Medical Sciences, College of Medicine, National Cheng Kung University, Tainan 701, Taiwan
}

\begin{abstract}
The induction of hippocampal long-term synaptic plasticity is exquisitely sensitive to behavioral stress, but the underlying mechanisms are still unclear. We report here that hippocampal slices prepared from adult rats that had experienced unpredictable and inescapable restraint tail-shock stress showed marked impairments of long-term potentiation (LTP) in the CA1 region. The same stress promoted the induction of long-term depression (LTD). These effects were prevented when the animals were given the glucocorticoid receptor antagonist 11 $\beta, 17 \beta$-11[4-(dimethylamino)phenyl]-17-hydroxy-17-(1-propynyl)-estra-4-9-dien-3-one before the stress. Immunoblotting analyses revealed that stress induced a profound and prolonged extracellular signal-regulated kinase/mitogen-activated protein kinase (ERK1/2 MAPK) hyperphosphorylation through small GTPase Ras, Raf-1, and MAPK kinase 1/2 (MEK1/2). Furthermore, the stress effects were obviated by the intrahippocampal injection of specific inhibitors of MEK1/2 (U0126), protein kinase C (bisindolylmaleimide I), tyrosine kinase (K252a), and BDNF antisense oligonucleotides. These results suggest that the effects of stress on LTP and LTD originate from the corticosterone-induced sustained activation of ERK1/2-coupled signaling cascades.
\end{abstract}

Key words: stress; long-term potentiation; long-term depression; extracellular signal-related kinase; mitogen-activated protein kinase; glucocorticoid receptor; hippocampus

\section{Introduction}

Stress underlies many psychological and physical problems. In particular, learning and memory are dramatically modified by stress (Lupien and Lepage, 2001). In the case of hippocampaldependent learning and memory, stress facilitates or blocks the acquisition, consolidation, or recall of such tasks, depending on its severity and context (Kim and Diamond, 2002). Consistent with these behavioral observations, both in vitro and in vivo electrophysiological studies indicate that stress impairs hippocampal long-term potentiation (LTP) (Kim et al., 1996; Xu et al., 1997), a putative cellular mechanism underlying learning and memory (Martin et al., 2000). In contrast, low-frequency stimulation (LFS)-induced long-term depression (LTD) is promoted by such stress (Kim et al., 1996; Xu et al., 1997). If the notion that changes in synaptic efficacy are essential for learning and memory processes is correct, then it is possible that LTP impairment associated with stress might be one neural basis for stress-mediated memory storage deficit. However, the molecular and cellular

Received May 12, 2004; revised 0ct. 29, 2004; accepted 0ct. 29, 2004.

This work was supported by a research grant from the National Health Research Institute (NHRI-EX92-9215NI) of Taipei, Taiwan.

Correspondence should be addressed to Dr. Kuei-Sen Hsu, Department of Pharmacology, College of Medicine, National Cheng Kung University, Number 1, University Road, Tainan 701, Taiwan. E-mail: richard@mail.ncku.edu.tw. DOI:10.1523/JNEUROSCI.3968-04.2004

Copyright $\odot 2004$ Society for Neuroscience $\quad 0270-6474 / 04 / 2411029-06 \$ 15.00 / 0$ mechanisms underlying the alteration of the inducibility of LTP and LTD by stress are still unclear.

Here, we report our novel observations that the effects of stress on subsequent LTP and LTD induction are mediated through the activation of the glucocorticoid receptors, provoking expression and release of brain-derived neurotrophic factor (BDNF) to persistently activate the extracellular signal-regulated kinase (ERK) 1/2-coupling mechanisms.

\section{Materials and Methods}

Animals and stress protocol. Healthy adult male Sprague Dawley rats weighing 250-300 gm were used. Experimental protocols were approved by the National Cheng Kung University Institutional Animal Care and Use Committee. Animals were housed in groups of four in a vivarium with a $12 \mathrm{hr}$ light/dark cycle, 50-60\% humidity, and unrestricted access to food and water. Animals were allowed to acclimate to the laboratory $1-2$ weeks before the beginning of the experiments. Behavioral stress was evoked by 60 tail shocks ( $1 \mathrm{~mA}$ for $1 \mathrm{sec}, 30-90 \mathrm{sec}$ apart) while restrained in a Plexiglas tube. Plasma adrenocorticotropic hormone (ACTH) and corticosterone levels were determined by radioimmunoassay.

Electrophysiology. Animals were killed, and 400- $\mu$ m-thick hippocampal slices were prepared using standard procedures (Huang et al., 1999). After a minimum recovery period of $1 \mathrm{hr}$, the slices were transferred to a submersion-type recording chamber and were continually perfused with $30-32^{\circ} \mathrm{C}$ of an oxygenated artificial CSF solution comprising the following (in mM): $117 \mathrm{NaCl}, 4.7 \mathrm{KCl}, 2.5 \mathrm{CaCl}_{2}, 1.2 \mathrm{MgCl}_{2}, 25 \mathrm{NaHCO}_{3}, 1.2$ $\mathrm{NaH}_{2} \mathrm{PO}_{4}$, and 11 glucose. Extracellular recordings were performed with Axoclamp-2B amplifier (Axon Instruments, Union City, CA). The re- 
sponses were low-pass filtered at $2 \mathrm{kHz}$, digitally sampled at $5-10 \mathrm{kHz}$, and analyzed using pClamp software (version 8.0; Axon Instruments). The evoked postsynaptic responses were induced in CAl stratum radiatum by stimulation of Schaffer collateral-commissural afferents at $0.033 \mathrm{~Hz}$ with a bipolar stimulating electrode. Field EPSPs (fEPSPs) were recorded with a glass pipette filled with $1 \mathrm{M} \mathrm{NaCl}(2-3$ $\mathrm{M} \Omega$ resistance), and the initial slope was measured. LTP was induced by high-frequency stimulation (HFS) consisting of two 1 sec trains of stimuli separated by an intertrain interval of $20 \mathrm{sec}$ at $100 \mathrm{~Hz}$. LTD was induced using a standard protocol of 900 stimuli at $1 \mathrm{~Hz}$ (LFS).

Western blotting. The microdissected subregions were lysed in ice-cold Tris-HCl buffer solution, $\mathrm{pH} 7.4$, containing a mixture of protein phosphatase and proteinase inhibitors $(50 \mathrm{~mm}$ Tris- $\mathrm{HCl}, 100 \mathrm{~mm} \mathrm{NaCl}, 15 \mathrm{~mm}$ sodium pyrophosphate, $50 \mathrm{~mm}$ sodium fluoride, $1 \mathrm{~mm}$ sodium orthovanadate, 5 mm EGTA, 5 mM EDTA, $1 \mathrm{~mm}$ phenylmethylsulfonyl fluoride, $1 \mu \mathrm{M}$ microcystin-LR, $1 \mu \mathrm{M}$ okadaic acid, 0.5\% Triton X-100, $2 \mathrm{~mm}$ benzamidine, $60 \mu \mathrm{g} / \mathrm{ml}$ aprotinin, and $60 \mu \mathrm{g} / \mathrm{ml}$ leupeptin) to avoid dephosphorylation and degradation of proteins and ground with a pellet pestle. Samples were sonicated and spun down at $15,000 \times g$ at $4^{\circ} \mathrm{C}$ for 10 $\min$. The supernatant was then assayed for total protein concentration using Bio-Rad Bradford Protein Assay kit (Bio-Rad, Hercules, CA). The proteins in each sample were electrophoretically separated in a 10\% SDS-PAGE gel. After the transfer on nitrocellulose membranes, blots were blocked in TBS containing 3\% bovine serum albumin and $0.01 \%$ Tween 20 for $1 \mathrm{hr}$ and then blotted for $2 \mathrm{hr}$ at room temperature with antibodies that recognize phosphorylated ERK1/2 (1:1000; Cell Signaling Technologies, Beverly, MA), phosphorylated p38 mitogenactivated protein kinase (MAPK) (1:1000; Cell Signaling Technologies), phosphorylated Raf-1 (1:1000; Upstate Biotechnology, Lake Placid, NY), or phosphorylated MAPK kinase $1 / 2$ (MEK1/2) (1:1000; Cell Signaling Technologies). It was then probed with HRP-conjugated secondary antibody for $1 \mathrm{hr}$ and developed using the ECL immunoblotting detection system. The immunoblots using phosphorylation site-specific antibodies were subsequently stripped and reprobed with anti-ERK1/2 antibody (1:1000), anti-p38 MAPK antibody (1:500), and antiMEK1/2 antibody (1:500) (all from Cell Signaling Technologies) and antiRaf-1 antibody (1:1000) that was obtained from Santa Cruz Biotechnology (Santa Cruz, CA). The activity of Ras was determined using Ras activation assay kit (Upstate Biotechnology). Immunoblots were analyzed by densitometry.

BDNF immunoassay. BDNF levels were measured with a conventional two-site ELISA system according to the protocol of the manufacturer (Promega, Charbonniere, France). BDNF concentrations were calculated from regression analysis of a human recombinant BDNF standard curve run in each assay and expressed as normalized per gram of tissue wet weight.

Protein kinase $C$ activity assay. Protein kinase C (PKC) activity was assessed using PepTag Assay for nonradioactive detection PKC (Promega) on the basis of the phosphorylation of fluorescent-tagged PKCspecific peptides. Briefly, the microdissected CA1 subregion of hippocampal slices was lysed in ice-cold TBS, homogenized, and centrifuged at $100,000 \times g$ for $30 \mathrm{~min}$. The pellet was rehomogenized in homogenization buffer and sonicated, incubated with Triton X-100 (0.2\%) for 30 $\mathrm{min}$, and centrifuged at $100,000 \times g$ for $30 \mathrm{~min}$. The supernatant con-
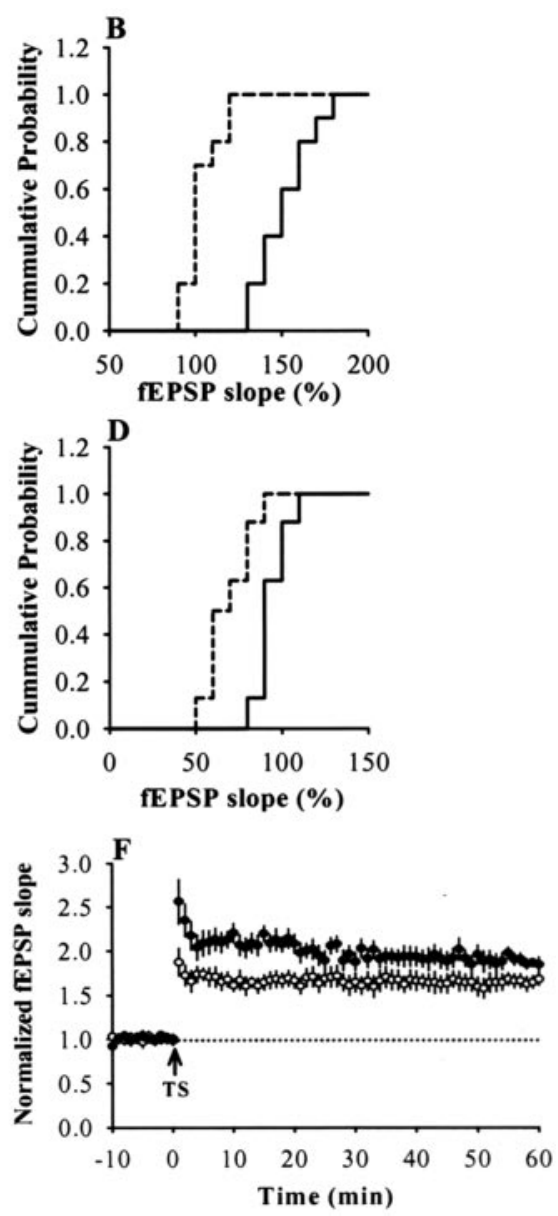

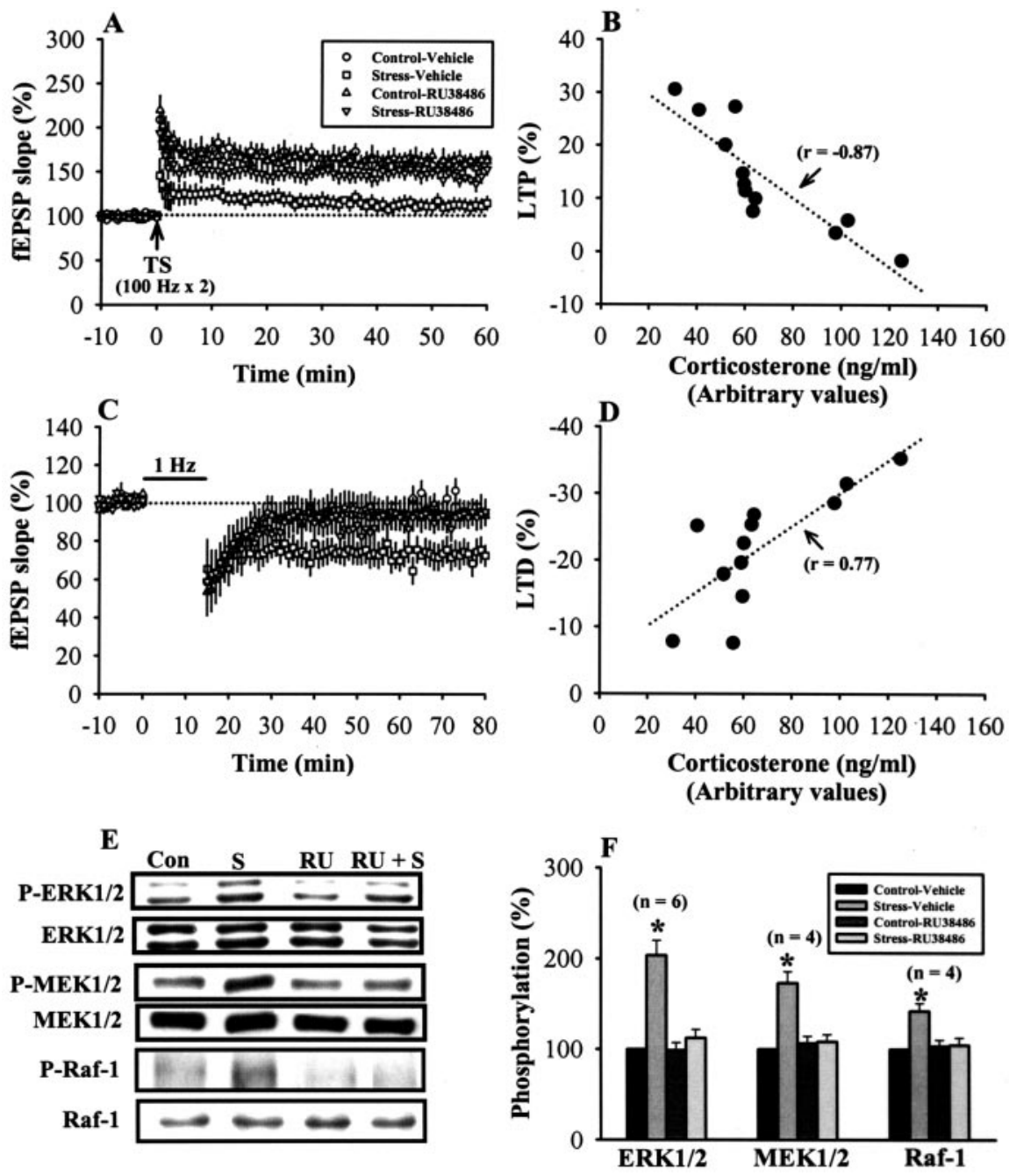

Figure 2. Activation of glucocorticoid receptors mediates the effects of stress on LTP and LTD. A, HFS induced robust LTP in slices from stressed rats administered RU38486. B, A significant negative linear correlation is evident between the elevated plasma corticosterone levels and LTP expression. C, LFS failed to induce LTD in slices from stressed rats administered RU38486. D, A significant positive linear correlation is evident between the elevated plasma corticosterone levels and LTD expression. $E$, Representative immunoblots show ERK1/2, MEK1/2, and Raf-1 phosphorylation after stress (S) with or without RU38486 (RU) treatment. The corresponding densitometric analysis is shown in $F .{ }^{*} p<0.05$. Con, Control; TS, tetanic stimulation.

bisindolylmaleimide V (BIS-V), K252a, K252b, U0126, and U0124 were obtained from Calbiochem (La Jolla, CA) and dissolved in dimethylsulfoxide. 11 $\beta, 17 \beta$-11[4-(dimethylamino)phenyl]-17-hydroxy-17(1-(propynyl)-estra-4,9-dien-3-one (RU38486) was purchased from Tocris Cookson (Bristol, UK) and dissolved in propylene glycol.

Data analysis. All data were expressed as the mean \pm SEM and, unless stated otherwise, the statistic significance was determined using the Mann-Whitney $U$ test. The number of animals used is indicated by $n$. Probability values of $p<0.05$ were considered to represent significant differences.

\section{Results}

\section{Influence of stress on LTP and LTD}

In response to stress, significantly higher levels of ACTH (564 \pm 64 vs $108 \pm 17 \mathrm{pg} / \mathrm{ml}$ in basal condition) and corticosterone concentrations $(116.5 \pm 6.9$ vs $9.8 \pm 2.7 \mathrm{ng} / \mathrm{ml}$ in basal condition) were observed (supplementary Fig. S1, available at www. jneurosci.org as supplemental material). To examine the effects of stress on long-term synaptic plasticity, we analyzed LTP and LTD in the hippocampal CA1 region. When LTP was assessed after HFS, hippocampal slices from stressed rats exhibited im- paired LTP $(105.8 \pm 7.6 \%$ of baseline; $n=$ $8 ; p<0.05)$ compared with slices from control rats $(156.2 \pm 7.8 \%$ of baseline; $n=$ 8) (Fig. $1 A, B$ ). LFS in hippocampal slices from control rats failed to evoke LTD $(94.2 \pm 5.1 \%$ of baseline; $n=8)$. In contrast, slices from stressed rats showed robust LTD ( $67.8 \pm 6.4 \%$ of baseline; $n=8$; $p<0.05$ ) (Fig. 1C,D).

Because LTP is saturable (Bliss and Collingridge, 1993), it is possible that stress produces LTP-like changes in the hippocampus and then the subsequent LTP was occluded (Shors and Thompson, 1992; Diamond et al., 2004). To depotentiate the synaptic strength, LFS was repeatedly applied until there was no more depression and, after depression was stabilized, HFS was then delivered to induce LTP. In these experiments, we found that LTP elicited in slices from stressed rats showed a duration and magnitude that was not statistically different from those observed in slices from control rats (Fig. $1 E, F$ ), consistent with the suggestion that stress impairs LTP by perhaps sharing the same molecular machinery required to support LTP.

Putative mechanisms of effects of stress To examine the role of glucocorticoid receptor activation in mediating the effects of stress on LTP and LTD, the specific glucocorticoid receptor antagonist RU38486 $(40 \mathrm{mg} / \mathrm{kg})$ was intraperitoneally injected 30 min before stress. As shown in Figure 2, the effects of stress were completely prevented by RU38486. HFS induced robust LTP in hippocampal slices from stressed rats that were administered RU38486 $(147.8 \pm 6.9 \%$ of baseline; $n=5$ ) (Fig. $2 A)$. Moreover, there was a significant negative linear correlation between the elevated plasma corticosterone levels and LTP expression (Fig. $2 B$ ) (correlation coefficient, $r=-0.87 ; p<$ $0.001)$. RU38486 also blocked the facilitation of LTD by stress $(91.8 \pm 6.9 \%$ of baseline; $n=4)$ (Fig. $2 C$ ). A significant positive linear correlation was evident between the elevated plasma corticosterone levels and LTD expression (Fig. 2D) (correlation coefficient, $r=0.77 ; p<0.001)$.

Having confirmed the role of glucocorticoid receptor activation in mediating the effects of stress, we subsequently investigated whether MAPK-coupled signaling pathways might act downstream of glucocorticoid receptors to exert the stress effects. Consistent with this speculation, ERK2 can be rapidly activated in the amygdala following acquisition spatial task in stress conditions (Akirav et al., 2001), and corticosterone can rapidly activate ERK1/2 in PC12 cells via putative membrane receptors (Qiu et al., 2001). Figure $3 A$ shows the time course of ERK1/2 phosphorylation after stress. Densitometric analysis revealed a significant increase of ERK1/2 phosphorylation at $0-12 \mathrm{hr}$ after stress.

To determine whether the Ras/Raf-1/MEK1/2 signaling lies upstream of ERK1/2 to mediate stress effects, we conducted a 
series of experiments to measure the Ras, Raf-1, and MEK1/2 activities in hippocampal slices from stressed rats. As shown in Figure $3 B$, phosphorylated MEK1/2 levels were strongly upregulated in slices obtained from stressed rats. A significant increase of MEK $1 / 2$ phosphorylation was observed $0-6 \mathrm{hr}$ after stress. In addition, a significant increase in the Raf- 1 phosphorylation was observed immediately after stress and $1 \mathrm{hr}$ later (Fig. 3C). Furthermore, the amount of active (GTP bound) Ras was significantly larger in slices from stressed rats, compared with the amount in hippocampal slices obtained from control rats (Fig. 3D). However, stress had no detectable effects on p38 MAPK phosphorylation (Fig. 3E). Treatment of rats with RU38486 before stress completely prevented the stressinduced activation of Ras, Raf-1, MEK1/2, and ERK1/2 MAP (Figs. 2E, F, 3D).

To further explore the possibility of a causal relationship between the MEK1/2ERK $1 / 2$ activation and stress effects, we performed parallel electrophysiological studies to examine the inducibility of LTP and LTD in hippocampal slices from rats treated with the MEK1/2 inhibitor U0126 (2 $\mu \mathrm{g} / \mu \mathrm{l}$, bilateral intrahippocampal injection $1 \mathrm{hr}$ before stress). Reliable LTP was elicited ( $152.3 \pm 8.6 \%$ of baseline; $n=$ 3 ) and LTD was no longer induced ( $95.5 \pm$ $6.7 \%$ of baseline; $n=3$ ) in slices from stressed rats that received U0126 (Fig. $3 F, G)$. Similarly, U0126 also essentially blocked the stress-induced increase in ERK1/2 phosphorylation (Fig. 3G). In contrast, the inactive analog U0124 did not significantly affect the stress effects (supplementary Figs. S2 and S3, available at www.jneurosci.org as supplemental material).

Because BDNF plays an important role as a mediator of stress response (Marmigere et al., 2003) and may act on the tyrosine receptor kinase $B(\operatorname{TrkB})$ receptors to initiate the sequential phosphorylation of adapter molecules and then activate Ras-dependent signaling, the rapid increase in BDNF expression during stress exposure could result in the activation of ERK1/2 signaling pathways via the glucocorticoid receptors. To examine this possibility, we examined the inducibility of LTP and LTD in hippocampal slices from rats that received intracerebroventricular injections of BDNF antisense and sense oligonucleotides (50 pmol twice per day for $5 \mathrm{~d}$, bilateral injection). This regimen completely prevented the blockade of LTP induction $(143.6 \pm 9.2 \%$ of baseline; $n=4)$ and the facilitation of LTD $(95.1 \pm 6.4 \%$ of baseline; $n=$ 4 ) by stress (Fig. $4 A, B$ ). In contrast, BDNF sense oligonucleotide treatment did not show any influence on the effects of stress.
Time after stress (hr)
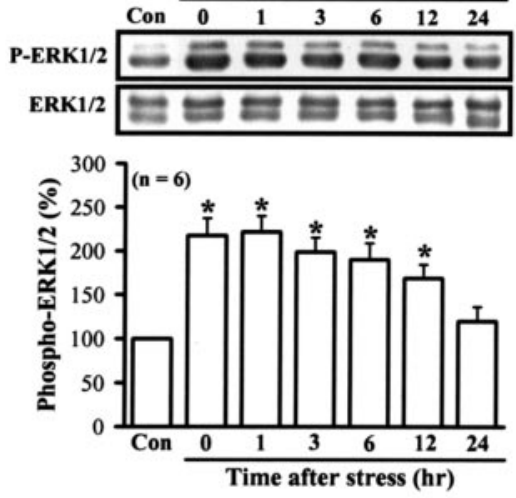

B
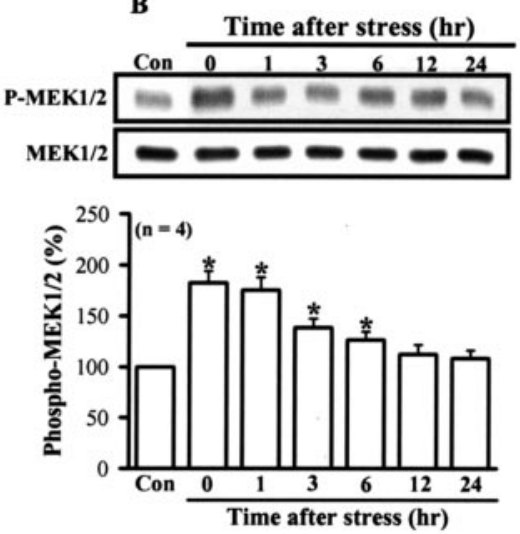

C
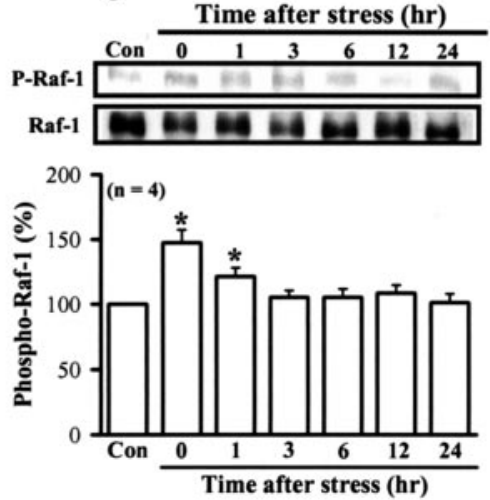
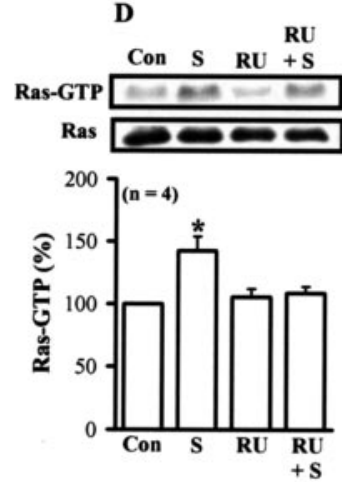

E Time after stress (hr)
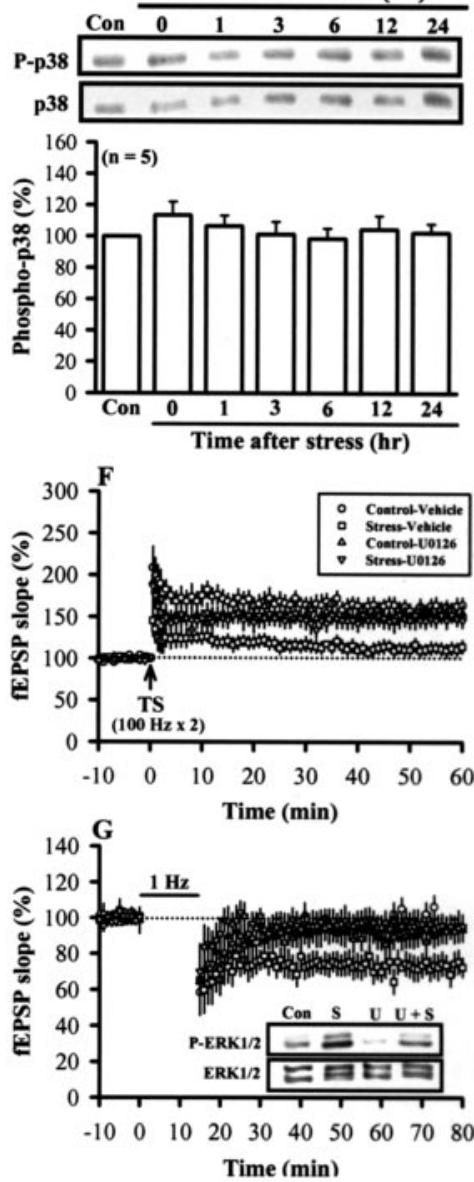

Figure 3. Stress induces a sustained activation of ERK1/2 signaling cascade. $A$, Representative immunoblot and corresponding densitometric analysis show time course of ERK1/2 phosphorylation after stress. $B$, Representative immunoblot and corresponding densitometric analysis show time course of MEK1/2 phosphorylation at various time points after stress. $C$, Representative immunoblot and corresponding densitometric analysis show time course of Raf- 1 phosphorylation after stress. $D$, Representative immunoblot and corresponding densitometric analysis show the effect of stress (S) on Ras-GTP level. E, Representative immunoblot and corresponding densitometric analysis show the time course of p38 MAPK phosphorylation after stress. $F$, HFS induced a reliable LTP in slices from stressed rats administered U0126. G, LFS failed to induce a reliable LTD in slices from stressed rats administered U0126. Inset, Western blotting shows that stress-induced increase in ERK1/2 phosphorylation was prevented by U0126 treatment. ${ }^{*} p<0.05$. Con, Control; RU, RU38486.

BDNF antisense oligonucleotide treatment also essentially blocked the stress-induced increase in ERK1/2 phosphorylation (Fig. $4 I$ ). Figure $4 F$ shows that the BDNF protein levels in the hippocampi of antisense oligonucleotide-treated rats were significantly lower than those in vehicle or sense oligonucleotidetreated rats. Likewise, treatment of rats with RU38486 also completely prevented the stress-induced increase in BDNF synthesis. 

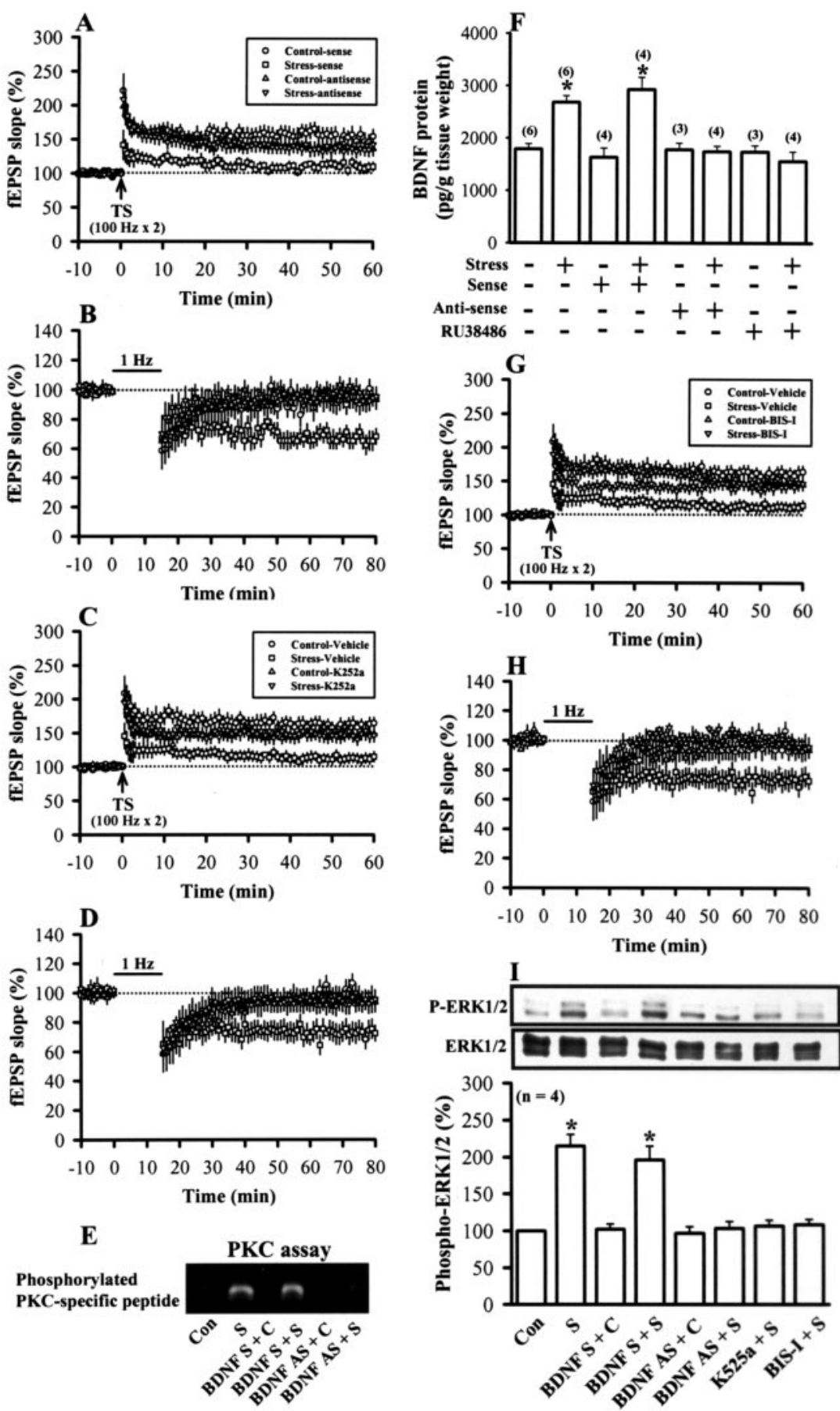

Figure 4. BDNF signaling mediates the effects of stress on LTP and LTD. A, HFS induced a reliable LTP in slices from stressed rats that received BDNF antisense oligonucleotide. $B$, LFS failed to induce LTD in slices from stressed rats that received BDNF antisense oligonucleotide. C, HFS induced a reliable LTP in slices from stressed rats that received K252a. D, K252a administration overcame the stress-induced facilitation of LTD. E, The stress-induced increased PKC activation in the hippocampal CA1 region was significantly blocked by BDNF antisense oligonucleotide treatment. F, Administration of BDNF antisense oligonucleotide or RU38486 blocked the stress-induced increase in BDNF protein levels in the whole rat hippocampi. G, HFS induced a reliable LTP in slices from stressed rats that received PKC inhibitor BIS-I. H, BIS-I administration overcame the stress-induced facilitation of LTD. I, Stressinduced increased ERK1/2 phosphorylation is significantly blocked by BDNF antisense oligonucleotide, K252a, or BIS-I treatment. The corresponding densitometric analysis is shown below. ${ }^{*} p<0.05$. BDNF $S$, BDNF sense oligonucleotide; BDNF AS, BDNF antisense oligonucleotide; C, control animal without stress; Con, control; S, stress; TS, tetanic stimulation.

To test whether BDNF contributes to the stress effects through the activation of $\operatorname{TrkB}$ receptors, a permeable nonspecific $\operatorname{TrkB}$ receptor antagonist (K252a; $0.5 \mu \mathrm{g} / \mu \mathrm{l})$ was administrated via bilateral intrahippocampal injection $1 \mathrm{hr}$ before stress. As shown in Figure $4, C$ and $D$, treatment with K252a completely prevented the blockade of LTP $(142.8 \pm 9.1 \%$ of baseline; $n=3)$ and the facilitation of LTD $(92.6 \pm 6.5 \%$ of baseline; $n=3$ ) by stress. In contrast, treatment with a weaker inhibitor of Trk-type kinase, K252b, did not significantly affect the stress effects (supplementary Figs. S2C and S2D, available at www.jneurosci.org as supplemental material). Likewise, K252a but not K252b treatment also prevented the stress-induced increase in ERK1/2 phosphorylation (Fig. 4I) (supplementary Fig. S3, available at www. jneurosci.org as supplemental material).

To determine whether PKC mediates the effects induced by BDNF on ERK1/2 activation, we assayed PKC activity in the hippocampal CA1 subregion homogenates. Under basal conditions, PKC activity was low in control rats. In contrast, PKC activity was significantly increased in stressed rats, which could be prevented by treatment with BDNF antisense oligonucleotide $(n=4)$ (Fig. 4E). Moreover, we also examined the inducibility of LTP and LTD in slices from rats that received BIS-I $(0.2 \mu \mathrm{g} / \mu \mathrm{l})$, a specific inhibitor of PKC, which was intrahippocampally administrated $1 \mathrm{hr}$ before stress. BIS-I completely prevented the stress-induced suppression of LTP (142.1 $\pm 7.6 \%$ of baseline; $n=3$ ) (Fig. 4G). The facilitation of LTD by stress was also completely prevented (98.7 \pm $5.9 \%$ of baseline; $n=3$ ) (Fig. $4 H$ ). In contrast, the inactive analog BIS-V did not significantly affect the effects of stress (supplementary Figs. S2E and S2F, available at www.jneurosci.org as supplemental material). The stress-induced increase in ERK1/2 MAPK phosphorylation was also abolished by BIS-I (Fig. 4I) but not by BIS-V treatment (supplementary Fig. S3, available at www.jneurosci.org as supplemental material).

\section{Discussion}

The present study highlights a decisive role of ERK $1 / 2$ in the stress-induced alterations in the inducibility of LTP and LTD in the CA1 region of the hippocampus. Our findings demonstrate that acute stress increases the circulating corticosterone levels, leading to the activation of glucocorticoid receptors and subsequently provoking the synthesis and release of BDNF acting on the TrkB receptor. The end result is the activation of a sequential kinase cascade that includes PKC, Ras/Raf-1, MEK1/2, and ERK1/2. The activated ERK1/2 drives its downstream signaling compartments and impairs the LTP induction and promotes the induction of LTD.

ERK1/2 signaling is a highly conserved kinase cascade linking 
the transmembrane receptors to downstream effector mechanisms. Neuronal ERK1/2 activation is correlated with and necessary for different hippocampal learning paradigms such as contextual fear conditioning (Atkins et al., 1998), spatial learning (Blum et al., 1999), and LTP (English and Sweatt, 1996). In addition to its role in synaptic plasticity and various forms of memory formation, stressful spatial learning paradigms increase ERK2 activation in both the hippocampus and amygdala (Akirav et al., 2001). The complex pattern of ERK $1 / 2$ in regulating cognitive functions appears to be relevant to the magnitude and duration of their activation. In the present study, the parallel in time course of the increased ERK1/2 activation and the effects of stress on LTP and LTD and pharmacological blockade of ERK1/2 completely prevented the stress effects strongly supports the suggestion for a critical role of sustained activation of ERK1/2 in mediating the blockade of LTP and the facilitation of LTD induced by stress.

What might be responsible for this apparent dissociation? One possibility is that sustained activation of ERK1/2 activates some molecular machinery required to support LTP, which in turn occludes subsequent LTP induction. Under this scenario, processes that decrease synaptic strength such as LTD and depotentiation should be facilitated after stress. Indeed, we found that stress impairs the induction of LTP but promotes the induction of LTD and that, in hippocampal slices obtained from stressed rats, LTP is normally elicited when tetanus is applied after LTD has been established previously. The underlying mechanism(s) that gate the reversibility of stress-induced LTP impairment by LFS is not well understood. Our findings establish one possible mechanism by which the sustained activation of ERK1/2 after stress experience is reversed by LFS. In fact, LTD in the hippocampal CA1 region in vivo can lead to a protein phosphatasedependent decrease in ERK1/2 activity (Norman et al., 2000).

How might glucocorticoid receptor activation lead to the sustained ERK1/2 activation? Our results clearly demonstrate that the best understood MAPK signaling transduction pathway of mammalian cells formed by Ras/Raf-1/MEK1/2 (Hagemann and Blank, 2001) lies upstream of ERK1/2 to regulate its activation. A recent study has described that stress might directly or indirectly trigger an increase in BDNF in the hippocampus, which may be a compensatory response to preserve hippocampal homeostasis or a form of neuronal plasticity to cope with stress stimuli (Marmigere et al., 2003). In line with these observations, our results demonstrate that stress induces a significant increase in BDNF levels in the rat hippocampi and that the intracerebroventricular injection of BDNF antisense oligonucleotides completely prevents this increase and the effects of stress on ERK1/2 activation and subsequent LTP and LTD induction. Furthermore, we found that the stress-induced ERK1/2 activation is suppressed by the PKC inhibitor, and BDNF antisense oligonucleotide significantly decreases the stress-induced PKC activation. On the basis of these results, we speculate that the increased BDNF synthesis after stress may underlie the effects of stress in the hippocampus and that PKC could act downstream of BDNF to mediate the activation of Ras/ERK1/2 MAPK signaling pathways by stress.

It is unknown which downstream targets of ERK1/2 mediate the stress effects. Because activated ERK1/2 can promote the activation of many ion channels, neurotransmitter receptors, protein kinases, and transcription factors, the potential candidates are numerous. Although the precise targeting substrates for ERK $1 / 2$ remain to be determined, the most promising candidates are A-type $\mathrm{K}^{+}$channel Kv4.2 and cAMP response element binding protein, which can be regulated by ERK1/2-mediated phos- phorylation and can play a key role in regulating the induction of hippocampal CA1 LTP (Impey et al., 1996).

In conclusion, the present study emphasizes the importance of activation of ERK1/2 signaling pathway, not only in the direct mediation of synaptic plasticity but also in the metaplastic determination of the polarity of subsequent synaptic plasticity. Our results also support an idea that stress affects subsequent hippocampal plasticity by sharing the same molecular machinery required to support LTP. These findings provide new insights into the molecular mechanisms underlying stress-related memory disorders, which, in turn, might provide novel opportunities for the development of more selective medication that targets these pathways and prevents their malfunction.

\section{References}

Acheson A, Conover JC, Fandl JP, DeChiara TM, Russell M, Thadani A, Squinto SP, Yancopoulos GD, Lindsay RM (1995) A BDNF autocrine loop in adult sensory neurons prevents cell death. Nature 374:450-453.

Akirav I, Sandi C, Richter-Levin G (2001) Differential activation of hippocampus and amygdala following spatial learning under stress. Eur J Neurosci 14:719-725.

Atkins CM, Selcher JC, Petraitis JJ, Trzaskos JM, Sweatt JD (1998) The MAPK cascade is required for mammalian associative learning. Nat Neurosci 1:602-609.

Bliss TV, Collingridge GL (1993) A synaptic model of memory: long-term potentiation in the hippocampus. Nature 361:31-39.

Blum S, Moore AN, Adams F, Dash PK (1999) A mitogen-activated protein kinase cascade in the CA1/CA2 subfield of the dorsal hippocampus is essential for long-term spatial memory. J Neurosci 19:3535-3544.

Diamond DM, Park CR, Woodson JC (2004) Stress generates emotional memories and retrograde amnesia by inducing an endogenous form of hippocampal LTP. Hippocampus 14:281-291.

English JD, Sweatt JD (1996) Activation of p42 mitogen-activated protein kinase in hippocampal long term potentiation. J Biol Chem 271:24329-24332.

Hagemann C, Blank JL (2001) The ups and downs of MEK kinase interactions. Cell Signal 13:863-875.

Huang CC, Liang YC, Hsu KS (1999) A role for extracellular adenosine in time-dependent reversal of long-term potentiation by low-frequency stimulation at hippocampal CA1 synapses. J Neurosci 19:9728-9738.

Impey S, Mark M, Villacres EC, Poser S, Chavkin C, Storm DR (1996) Induction of CRE-mediated gene expression by stimuli that generate longlasting LTP in area CA1 of the hippocampus. Neuron 16:973-982.

Kim JJ, Diamond DM (2002) The stressed hippocampus, synaptic plasticity and lost memories. Nat Rev Neurosci 3:453-462.

Kim JJ, Foy MR, Thompson RF (1996) Behavioral stress modifies hippocampal plasticity through $N$-methyl-D-aspartate receptor activation. Proc Natl Acad Sci USA 93:4750-4753.

Lupien SJ, Lepage M (2001) Stress, memory, and the hippocampus: can't live with it, can't live without it. Behav Brain Res 127:137-158.

Marmigere F, Givalois L, Rage F, Arancibia S, Tapia-Arancibia L (2003) Rapid induction of BDNF expression in the hippocampus during immobilization stress challenge in adult rats. Hippocampus 13:646-655.

Martin SJ, Grimwood PD, Morris RG (2000) Synaptic plasticity and memory: an evaluation of the hypothesis. Annu Rev Neurosci 23:649-711.

Norman ED, Thiels E, Barrionuevo G, Klann E (2000) Long-term depression in the hippocampus in vivo is associated with protein phosphatasedependent alterations in extracellular signal-regulated kinase. J Neurochem 74:192-198.

Paxinos G, Watson C (1997) The rat brain in stereotaxic coordinates. San Diego: Academic

Qiu J, Wang P, Jing Q, Zhang W, Li X, Zhong Y, Sun G, Pei G, Chen Y (2001) Rapid activation of ERK1/2 mitogen-activated protein kinase by corticosterone in PC12 cells. Biochem Biophys Res Commun 287:1017-1024.

Shors TJ, Thompson RF (1992) Acute stress impairs (or induces) synaptic long-term potentiation (LTP) but does not affect paired-pulse facilitation in the stratum radiatum of rat hippocampus. Synapse 11:262-265.

Xu L, Anwyl R, Rowan MJ (1997) Behavioural stress facilitates the induction of long-term depression in the hippocampus. Nature 387:497-500. 